\title{
Central Neural Circuitry in the Jellyfish Aglantha
}

\section{A Model 'Simple Nervous System'}

\author{
George O. Mackie \\ Biology Department, University of Victoria, Victoria, B.C., Canada
}

\author{
Key Words \\ Cnidaria - Medusa $\cdot$ Hydromedusa $\cdot$ Nerve net $\cdot$ Hair cell . \\ Giant axon - Epithelial conduction · FMRFamide - Neural \\ network - Escape behavior
}

\begin{abstract}
Like other hydrozoan medusae, Aglantha lacks a brain, but the two marginal nerve rings function together as a central nervous system. Twelve neuronal and two excitable epithelial conduction systems are described and their interactions summarized. Aglantha differs from most medusae in having giant axons. It can swim and contract its tentacles in two distinct ways (escape and slow). Escape responses are mediated primarily by giant axons but conventional interneurons are also involved in transmission of information within the nerve rings during one form of escape behavior. Surprisingly, giant axons provide the motor pathway to the swim muscles in both escape and slow swimming. This is possible because these axons can conduct calcium spikes as well as sodium spikes and do so on an either/or basis without overlap. The synaptic and ionic bases for these responses are reviewed. During feeding, the manubrium performs highly accurate flexions to points at the margin. At the same time, the oral lips flare open. The directional flexions are conducted by FMRFamide immunore-
\end{abstract}

active nerves, the lip flaring by an excitable epithelium lining the radial canals. Inhibition of swimming during feeding is due to impulses propagated centrifugally in the same epithelium. Aglantha probably evolved from an ancestor possessing a relatively simple wiring plan, as seen in other hydromedusae. Acquisition of giant axons resulted in considerable modification of this basic plan, and required novel solutions to the problems of integrating escape with non-escape circuitry.

Copyright $\odot 2004$ S. Karger AG, Basel

\section{Introduction}

The term 'central nervous system' can legitimately be applied to hydromedusan nervous systems as these animals have concentrations of hundreds of axons running in parallel forming 'nerve rings' in the margin. There are two such rings, an inner and an outer (fig. 1C), but axonal processes cross between them at many points and the two rings essentially function as single unit. In cross sections of the nerve rings of Aglantha, a total of about 800 axon profiles are seen, most of them less than $1 \mu \mathrm{m}$ in diameter. As in medusae generally [1] they lack glial sheaths, although bundles of axons are sometimes partially separated by epithelial processes. In all species investigated the nerve rings include several functionally distinct nerve

\begin{tabular}{ll}
\hline KARGER & ( ) 2004 S. Karger AG, Basel \\
1424-862X/04/0132-0005\$21.00/0 \\
$\begin{array}{l}\text { Fax+41613061234 } \\
\text { www. karger@com }\end{array}$ & $\begin{array}{l}\text { Accessible online at: } \\
\text { www.karger.com/nsg }\end{array}$
\end{tabular}

\author{
Dr. G.O. Mackie \\ Biology Department \\ University of Victoria \\ Victoria, B.C., V8W $3 \mathrm{~N} 5$ (Canada) \\ Tel. +1 250721 7146, Fax +1 250721 7120, E-Mail mackie@uvic.ca
}




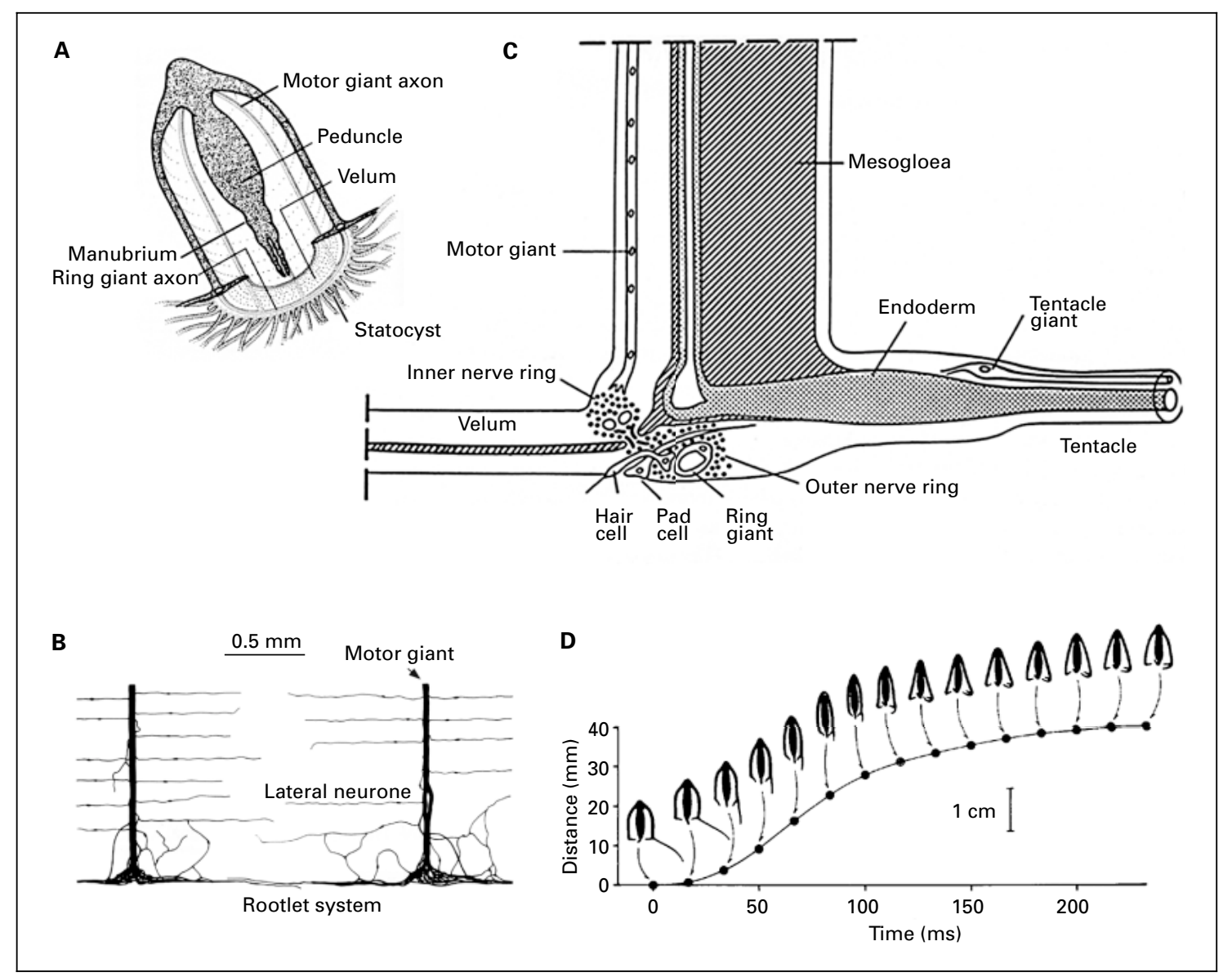

Fig. 1. Anatomy. A Aglantha cut in half vertically [15]. B Schematic representation of neighboring motor giant axons injected with Lucifer yellow. The dye has penetrated the lateral neurons and the system of rootlet interneurons [48]. C Perradial section through the margin. There are about 800 neurons in a typical cross section through the nerve rings, most of them less than $1.0 \mu \mathrm{m}$ in diameter. Nerves cross

pathways, and they often interact in complex ways. The fact that the central nervous system takes the form of an annulus rather than a single, compact ganglion does not make it any less 'central' in terms of the functions carried on within it. The annular configuration is simply an adaptation to radial symmetry $[2,3]$. It does mean, however, that pacemakers $[4,5]$ and synaptic interactions are replicated at numerous points around the ring, rather than being localized to specific zones as in the neuropil of a conventional ganglion. A practical advantage of the annular shape of the central nervous system is that a small piece of the margin containing part of the nerve ring can be cut out and pinned out for electrophysiology and it will have all the same systems and show the same synaptic interactions as the intact animal. the mesogloea between the inner and outer rings. The giant axons are conspicuously larger and both the ring and tentacle giants have prominent central vacuoles. The 'pad cell' is an enigmatic structure whose function is still not understood [57]. D Profiles of Aglantha during a single escape swimming contraction, showing distance travelled over time [15].

Hydromedusae differ in fundamental respects from jellyfish in the classes Scyphozoa and Cubozoa and no attempt will be made here to draw comparisons with members of these groups or to cover the extensive literature dealing with them. Fortunately, Satterlie's landmark review [6] covers nervous organization in all three classes, showing very clearly how they resemble one another and how they differ. Of the Hydromedusae, two species have been studied in most depth, Polyorchis penicillatus and Aglantha digitale. The focus here will be on Aglantha, where 14 physiologically distinct systems have been identified [7] but the Polyorchis work (summarized in [2, 8, 9]) offers instructive parallels and will be referred to frequently, along with work on several other species. 
Fig. 2. Circuitry. The principal pathways involved in locomotion, the control of tentacle contractions and food manipulation. Three of the eight longitudinal muscle bands lying in the wall of the manubrium are shown. Gap junctions are indicated by incomplete partitions between cells [39]. $\mathrm{C}=$ Carrier system; $\mathrm{E}_{\mathrm{n}}=$ endodermal epithelial pathway; $\mathrm{E}_{\mathrm{x}}=$ exumbrellar, ectodermal epithelial pathway; $F=$ flexion system used in pointing behaviour; $\mathrm{MG}=$ motor giant axon; $\mathrm{NO}=$ nitric oxide pathway; $\mathrm{P}=$ pacemaker system; $\mathrm{R}=$ relay system; ring giant $=$ ring giant axon; $\mathrm{RI}=$ rootlet interneurons; $\mathrm{TF}=$ the portion of the $\mathrm{F}$ system that originates in the tentacles; $\mathrm{TG}=$ tentacle giant axon; TS = slowly conducting tentacle system.

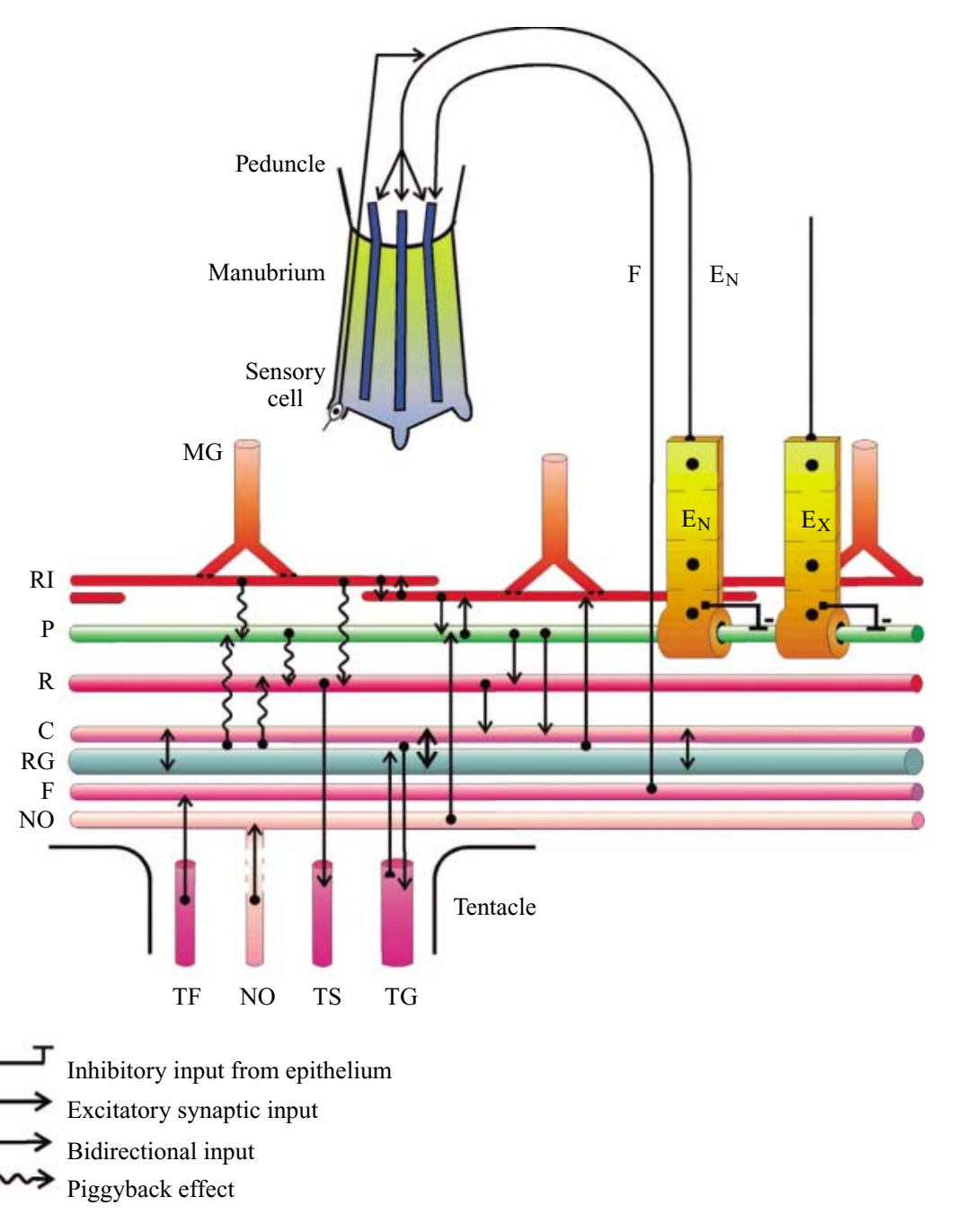

Aglantha digitale is a hydrozoan medusa in the family Rhopalonematidae. It is a small transparent jellyfish 1$2 \mathrm{~cm}$ long with numerous tentacles extending from around the lower margin (fig. 1A). Members of this family differ from typical hydromedusae in being pelagic throughout their entire life cycle, with no settled hydroid stage. Though sometimes brought to the surface by mixing or upwelling, Aglantha typically inhabits the mesopelagic realm of the sea. In the waters around Vancouver Island it lives at $50-200 \mathrm{~m}[10,11]$, but is also often found at the surface during the spring at the Friday Harbor Laboratories of the University of Washington, USA, where most of the work covered here was done.

References to Aglantha's nervous organization go back to the 19th century [12], but modern interest in the topic stems from (a) the observation that this jellyfish can swim in two distinct ways [13], and (b) the discovery of giant axons ('motor giants', fig. 1B, C) associated with the swim musculature [14]. The role of the giant axons in mediating one of the two forms of swimming (escape swimming, fig. 1D) was soon established $[15,16]$, but it has taken another 23 years for anything like a complete picture of the main circuitry to emerge [39] and many puzzles remain. I have tried here to draw attention to some of the major lacunae.

A problem facing Aglantha workers is the animal's small size and the difficulty of obtaining intracellular recordings from its neurons. Our analysis has depended heavily on extracellular recordings. This disadvantage is offset by the relative ease with which microelectrode 
recordings can be obtained from the swim muscles and from the giant axons. By studying the synaptic inputs into the giant axons while recording extracellularly from the nerve rings it has been possible to relate different input events to particular neural sub-systems and to build up a fairly comprehensive picture of the wiring (fig. 2). The reader may find it useful to refer to this figure frequently in the following pages even where it is not specifically cited, as it summarizes the whole story.

The present review covers the circuitry underlying the two sorts of swimming and associated tentacular contractions and summarizes recent findings on the pathways mediating feeding behaviour.

\section{Swimming}

There are two sorts of swimming, 'slow' and 'escape', and both employ the same effectors, the subumbrellar swim muscles. Slow swimming resembles the swimming of other hydromedusae, but escape swimming is unique to Aglantha and its relatives. The swim muscles lie in the ectoderm and are composed of myoepithelial cells whose striated, contractile processes run circularly forming a continuous sheet [14]. The cells are electrically coupled and current injected at one point depolarizes adjacent cells [18], but the spread is strictly local and propagated spikes have not been observed. This is contrary to the situation in most hydromedusae and siphonophores where myoid conduction is the norm, and the swimming motor neurons are, with a few exceptions [20], confined to the margin [2]. In Aglantha, excitation is spread across the muscle sheet by nerves, allowing the muscles to be excited in different ways during slow and escape swimming.

Both sorts of swimming are accompanied by contractions of the tentacles, but again these contractions are brought about in two different ways (see page 13).

\section{Slow Swimming}

Like other hydromedusae, Aglantha performs slow, rhythmic swimming when moving around normally. These contractions are generated endogenously by pacemaker neurons located in the inner marginal nerve ring (fig. 3A) and are exhibited in bursts of variable duration, sometimes at fairly regular intervals [21]. In certain, larger medusae (e.g. Polyorchis) it has been possible to record intracellularly from the equivalent units and to inject dyes [22, 23], but this has not been achieved in Aglantha, and we do not know how many neurons are involved or whether they are electrically coupled as in Polyorchis [23,
24]. In Aglantha they conduct circularly around the margin at velocities of $<0.5 \mathrm{~m} \cdot \mathrm{s}^{-1}$ [7], however, and presumably include some fairly large units.

Excitation spreads up the subumbrella from the margin rather slowly during slow swimming and the contractions evoked in the swim muscles are relatively weak, each propelling the animal only about one body length. The pacemaker neurons themselves are interneurons confined to the nerve rings and the excitation pathway was originally assumed [21] to be either the epithelium itself conducting in a myoid fashion, or a diffuse motor nerve net connecting the pacemaker neurons with the muscles, as had been suggested for certain Leptomedusae. Attempts to demonstrate such a net histologically in Aglantha, however, were unsuccessful and the possibility of non-nervous conduction in the myoepithelium could also be ruled out [18]. We already knew that there were eight motor giant axons running up from the margin into the muscle sheet (fig. 1B) and that they conducted rapidlypropagating $\left(<3.0 \mathrm{~m} \cdot \mathrm{s}^{-1}\right)$ sodium spikes during escape swimming $[15,16]$. The answer to how slow swimming is spread came unexpectedly when it was found that the same motor giant axons can also generate slowly-propagating $\left(<0.4 \mathrm{~m} \cdot \mathrm{s}^{-1}\right)$ calcium-based spikes [25]. Figure 3B1 shows one of these calcium spikes recorded from two sites along the axon. The spike retains its low amplitude and propagates without decrement. The sodium and calcium spikes are compared in figure $3 \mathrm{~B} 2$. The ability of the motor giants to conduct two sorts of propagated impulses is a phenomenon still without any known parallel in other organisms.

Transmission from the pacemaker neurons to the motor giants involves a slowly rising and slowly decaying EPSP (fig. 3A3). The example shown in figure $3 \mathrm{~A} 2$ has a calcium spike developing at its apex. The threshold for production of $\mathrm{Ca}^{2+}$ spikes is ca. $-51 \mathrm{mV}$, compared with $-33 \mathrm{mV}$ for $\mathrm{Na}^{+}$spikes [26]. As the peak of the calcium spike lies below the threshold for sodium spikes, calcium spikes do not trigger sodium spikes; thus, the two events can function independently in the two sorts of behavior. The ionic basis of these events is further discussed below (page 13).

The muscle contractions seen in slow swimming are weaker than those seen in escape, partly due to the lower amplitude and slower rise time of the post-synaptic depolarization and partly to the restriction of excitation to the region immediately adjacent to the motor giants, as excitation does not appear to be conducted out laterally across the muscle fields in this type of swimming [18]. 


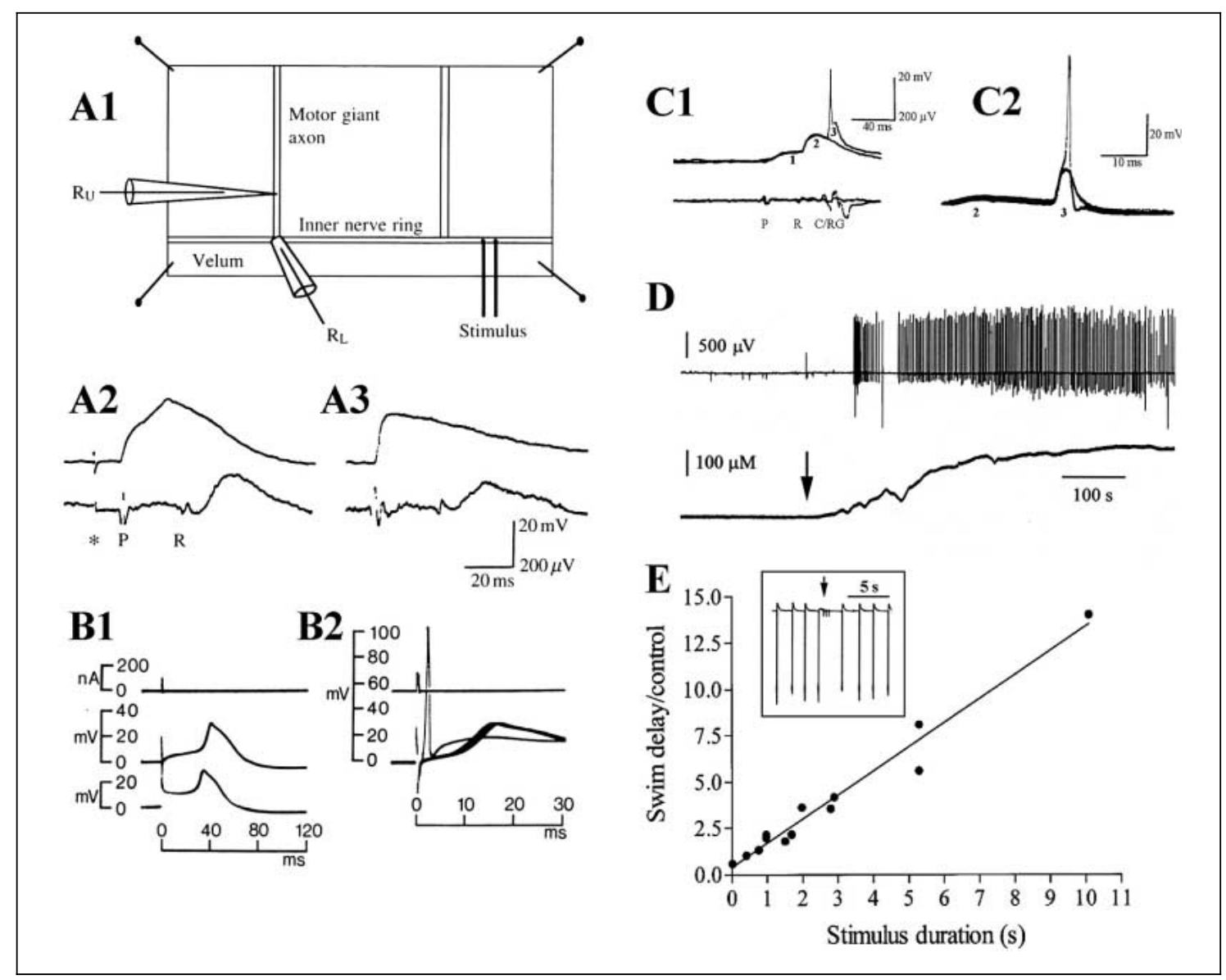

Fig. 3. Slow swimming records. A A typical preparation for recording from a motor giant axon is shown in A1. An intracellular electrode $\left(\mathrm{R}_{\mathrm{U}}\right)$ is inserted in the axon. An extracellular electrode $\left(\mathrm{R}_{\mathrm{L}}\right)$ records events in the nerve rings. Stimulation $(*)$ of the nerve ring excited the pacemaker system causing a slow EPSP in the motor giant that generated a calcium spike (upper trace in A2). A subthreshold EPSP is seen in A3. Pacemaker events invariably trigger activity in the relay system, whose extracellular correlates are seen ca. $27 \mathrm{~ms}$ after the pacemaker event in both A2 and A3 (lower traces). The following slow potential represents depolarization of epithelial cells in the vicinity of the nerve rings [57]. B With two electrodes inserted $2 \mathrm{~mm}$ apart in a motor giant, a brief injection of depolarizing current through one electrode evoked a propagated calcium spike (B1). A small increase in the intensity of injected current (top trace) resulted in a sodium spike (B2). Three superimposed calcium spikes are included in this figure for comparison [25]. C In C1, two superimposed sweeps are shown, both following single shocks to the nerve ring recorded extracellularly (lower trace) and intracellularly from

\section{Extrinsic Factors Affecting the Output of the Slow Swimming Pacemakers}

The swimming rhythm does not appear to be affected by variations in light intensity or water conditions, but these aspects have been little investigated. The absence of the ring giant axon (upper trace). The pacemaker, relay and carrier systems fired in sequence producing summing EPSPs (1,2 and 3, respectively) in the ring giant that caused the latter to spike in one case. Steps 2 and 3 in a similar cascade are shown expanded in C2 [57]. D Induction of swimming by nitric oxide. The NO donor DEA/ NO was added to the water bath (arrow) and the NO level was monitored by a NO-sensitive electrode placed beside the specimen (lower trace). When the concentration reached ca. $20 \mu M$, the animal responded by a long burst of slow swimming recorded as an electromyogram (upper trace) [70]. E Inhibition of swimming by epithelial impulses. The inset shows part of a regular swimming sequence (recorded electromyographically) interrupted briefly by the arrival of endodermal epithelial events evoked by stimulation (arrow) and propagated down the radial canals. The graph plots the relationship between the number of endodermal epithelial impulses (stimulus duration) and the resulting increase in the interval before the following swim, from a series of such experiments [39].

ocelli may not in itself mean that the animal is insensitive to light, as extraocular photosensitivity has been reported in many cnidarians $[27,28]$.

Swimming is strongly activated by low levels of nitric oxide (30-50 $\mathrm{n} M)$ in the water (fig. 3D). Neurons con- 
Fig. 4. Fine structure. A Phase-contrast image of the outer surface of the velum showing tactile combs (c), FMRFamide immunoreactive sensory cells (f) and the ring giant axon (rg) [44]. B Scanning electron micrograph of part of a tactile comb, showing hair cells with microvilli surrounding the cilium. The arrowhead shows the polarization of the microvillar collar toward the velum (v) [44]. C Orientation of hair cells on a tentacle base. Polarities are indicated by arrows and the proximo-distal axis of the tentacle is also shown (P-D) [44]. D Transmission electron micrograph showing a cross section through part of a motor giant axon (mg) and the bundle of small, FMRFamide immunoreactive axons $(\mathrm{F})$ that mediate the pointing response of the manubrium [57]. E Axons in the outer nerve ring labelled with anti-FMRFamide, with sensory cells (f) [39]. F Transmission electron micrograph of a cross section through part of the outer nerve ring containing the ring giant axon (rg) with its electron-dense central vacuole (vac). Small axons cluster around it [57].
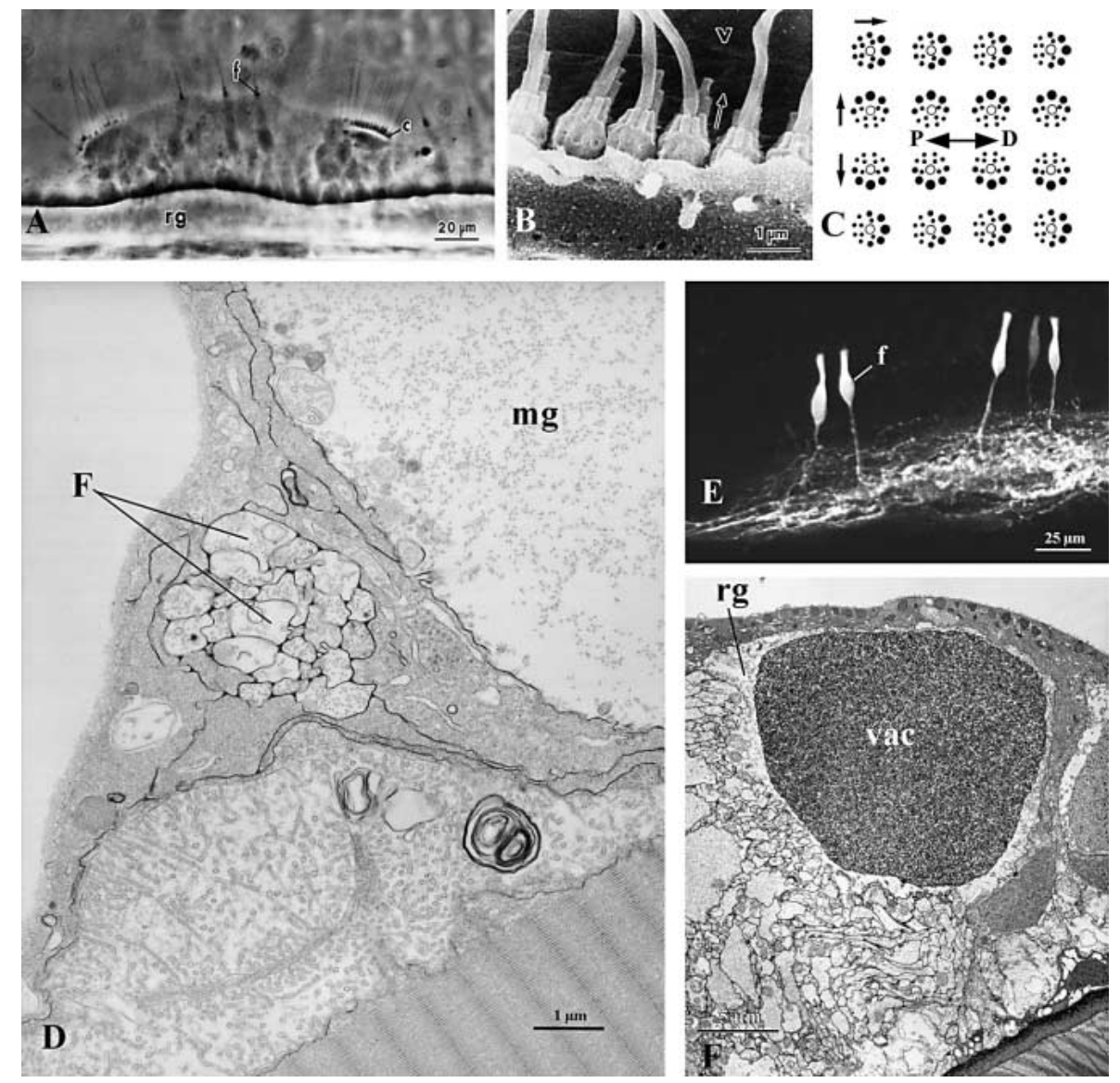

taining nitric oxide synthase are present in the tentacles and outer nerve ring, running in parallel with the pacemaker neurons, and it is likely that this system (NO in fig. 2) functions to modulate output of the pacemakers in nature, but precisely how is unknown [29, 70].

Like many other hydromedusae and siphonophores [for reviews, see 30-33], Aglantha has an excitable exumbrellar epithelium that propagates all-or-none impulses that spread across the epithelium. In the case of Aglantha this system ( $E_{x}$ in fig. 2 ) is not involved in the usual protective 'crumpling' response (involution of the margin). Indeed, adult Aglantha lack the radial and circular smooth muscles that bring this about. As in Stomotoca [34, 35] and Polyorchis [23], however, exumbrellar epithelial impulses do inhibit swimming [36]. A swimming animal making contact with another object would therefore stop swimming briefly. It is interesting that juvenile Aglantha have radial smooth muscles in the subumbrella, and may therefore be able to crumple. If so, they lose the ability later when their fast escape swimming responses become operational. The mechanism whereby exumbrel- lar epithelial impulses inhibit the swim pacemakers is not known, but in Polyorchis, large, long-lasting IPSPs have been recorded from the neurons during inhibition [23]. IPSPs have also been recorded from swim motor neurons in Aequorea [37] where they are associated with contractions of the radial muscles that overlie the swim muscle layer, but this response may be mediated by nerves (which are known to be associated with the radial muscles in several Leptomedusae [38]) rather than by excitable epithelia.

Swimming inhibition also occurs in the context of feeding (fig. 3E) [39], but here the pathway ( $E_{n}$ in fig. 2 ) is the epithelium forming the walls of the endodermal canals as discussed below, p. 16.

\section{Directionality of Slow Swimming}

Animals fishing for food generally sink passively with the bell inverted ('sink-fishing') [40]. Then, starting to swim, they veer around and swim upward ('righting'). Turning to swim upward is evidently dependent on input from the eight statocysts arranged around the margin 


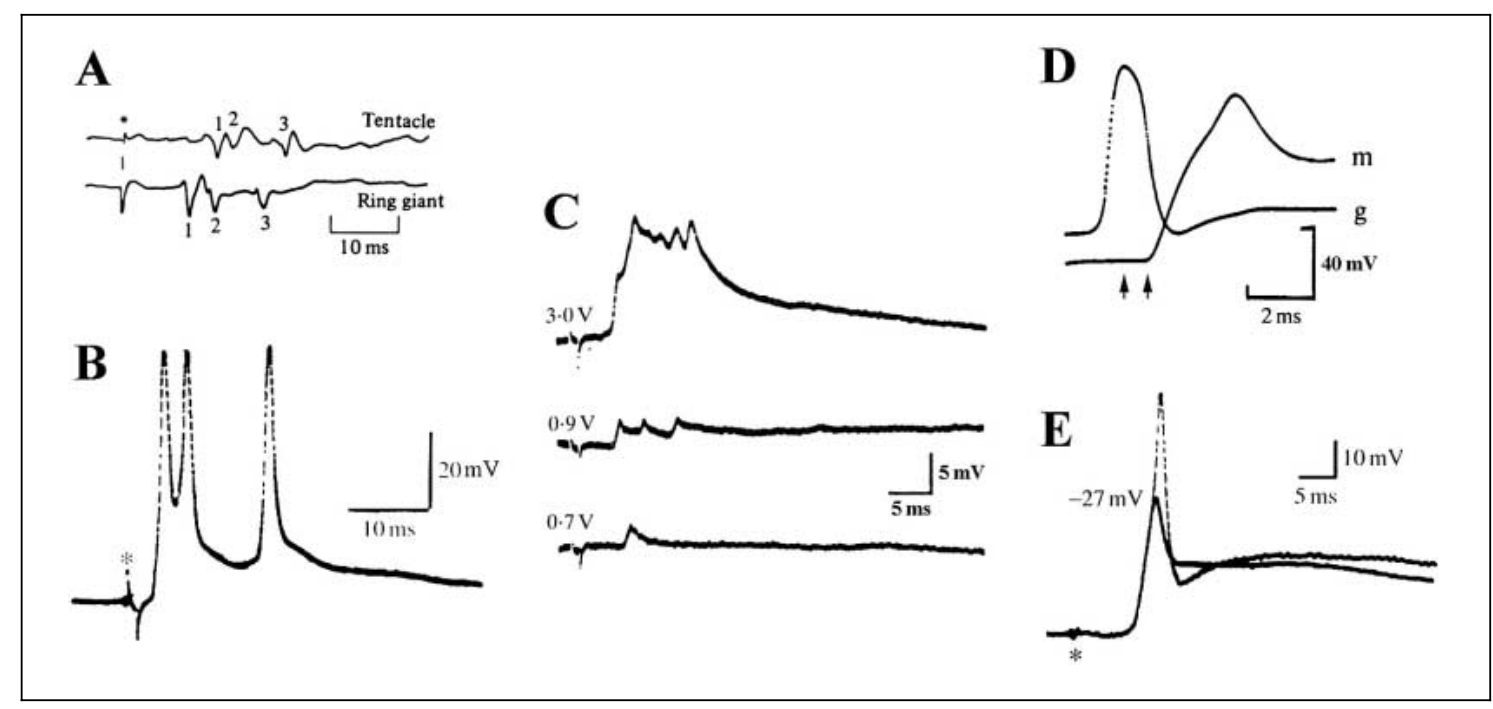

Fig. 5. Escape swimming records. A Extracellular recordings from a tentacle giant axon and the ring giant following a shock to the margin $\left.{ }^{*}\right)$ showing similar patterns of impulses in the two [16]. B Burst of three spikes recorded intracellularly from the ring giant axon following a shock to the outer nerve ring [58]. C EPSPs recorded from the ring giant following mechanical stimuli delivered to the velum by a probe mounted on a speaker coil. Voltages applied to the coil are shown on the left [44]. D Simultaneous intracellular records from a motor giant axon $(\mathrm{g})$ and a nearby $(80 \mu \mathrm{m})$ myoepithelial cell $(\mathrm{m})$ following stimulation of the motor giant. Arrows show the synaptic delay between the peak of the sodium spike and the start of the muscle spike [18]. E A shock on a motor giant generated a spike that propagated into rootlet interneurons producing either a spike or a subthreshold event in an adjacent motor giant. The subthreshold event (functionally an EPSP) is regarded as a rootlet spike attenuated by passage through gap junctions [7]. (fig. 1A) as after removal of these structures righting ability is lost [21]. The statocysts show structural features typical of gravity receptors [41] and their axons run into the outer nerve ring. There is no reason to suppose that statocyst input affects the swim pacemakers. Righting is probably brought about by asymmetric contraction of the velum during swimming as described for Polyorchis [42]. In both Aglantha and Polyorchis, the outer velar myoepithelium has radial muscle fibers, and is innervated by neurites from the outer nerve ring [38]. Impulses generated in activated statocysts probably excite these muscles selectively, deforming the velum on one side, but the precise way this happens has never been determined, and the system is omitted from the circuit diagram (fig. 2).

\section{Escape Swimming}

Escape swimming occurs in response to mechanical or electrical stimulation of the tentacles and of sites on the margin and subumbrella. The response has been repeatedly observed in large aquaria following contact with a predator [15] and clearly serves a defensive function. A single escape swim can propel the animal a distance equivalent to five body lengths with peak velocities up to $0.4 \mathrm{~m} \cdot \mathrm{s}^{-1}$ (fig. 1D). The response is mediated by rapidly-conducting giant axons. A single giant axon runs the length of each tentacle ('tentacle giant'), another runs circularly around the margin (fig. 4A, 'ring giant'), and as already noted a further set of eight 'motor giants' run radially up the subumbrella to the apex of the subumbrellar cavity (fig. 1B, C). The response evoked by stimulation on the 'outside' (outer margin and tentacles) differs from that seen following stimulation on the 'inside' (subumbrella) and the two will be considered separately.

Response to Outside Stimulation. Abrupt stimulation of one or more tentacles can evoke the escape response. Extracellular recordings [16] suggested that the tentacle giant axons were electrically coupled to the ring giant as they typically fired one-to-one with it (fig. 5A). However, the two systems do not appear to be in contact histologically [43], so the connections must be indirect, and may involve units of the carrier system (see below).

The ring giant also receives synaptic input from sensory cells located around the margin. Patterns of excitatory post-synaptic potentials (EPSPs) are recorded from the ring giant following mechanical displacements of the velum and tentacles (fig. 5C). The sensory cells responsible occur in clusters (fig. 4A, 'tactile combs') distributed 
around the velum and on the tentacle bases. They resemble vertebrate hair cells in having a cilium surrounded by a collar of microvilli graded in length from one side to the other (fig. 4B). They are arranged in rows where all the cells show the same polarity (fig. 4C). Unlike vertebrate hair cells they are primary sensory neurons and send an axon into the outer nerve ring to synapse with the ring giant. Laser ablation experiments have shown that responses to water-borne vibrations depend on the tactile combs, and they are therefore viewed as hydrodynamic receptor organs [44].

The ring giant axon characteristically fires in bursts of three or more spikes (fig. 5B), but only the first of these is transmitted to the motor giants during escape swimming. It is not clear why the following spikes are not transmitted. Transmission is chemical $[16,17]$ with large, fastrising EPSPs recorded in the motor giants near their bases [26], and occurs with a delay of ca. $1.6 \mathrm{~ms}$. Passage between the ring and motor giants is probably not direct, but may occur through a disynaptic link. The carrier system is probably involved here as its close association with the ring giant is known from other experiments (see below).

Because the ring giant conducts rapidly $\left(<2.6 \mathrm{~m} \cdot \mathrm{s}^{-1}\right)$ and in both directions around the margin, excitation reaches all eight motor giants almost simultaneously and contraction is virtually synchronous all around the margin. It is noteworthy that Polyorchis, a much larger animal, achieves synchrony in a completely different way, involving progressive reduction of synaptic delay as the impulse travels round the margin [45]. The motor giants generate sodium spikes (fig. 3B2) that propagate at velocities up to $4 \mathrm{~m} \cdot \mathrm{s}^{-1}$. They synapse directly with cells of the swim myoepithelium in their immediate vicinity through structurally polarized, chemical-type junctions [14]. Transmission is calcium-dependent and junctional delay has been measured at $0.7 \pm 0.1 \mathrm{~ms}$, making them among the fastest known invertebrate synapses [18] (fig. 5D). The motor giants are dye- (and presumably electrically-) coupled to a set of lateral neurons (fig. 1B) that run out sideways and excite interradial areas of the myoepithelium through chemical junctions [18]. The chemical identity of transmitters in the swim pathways has not yet been determined.

The combination of rapid conduction in giant axons, short delays at the neuromuscular junctions and rapid development of tension in the myoepithelium ensures a short overall response time and fast escape from potentially damaging sources of stimulation. Response latency, measured from stimulus to first detectable movement, is about $10 \mathrm{~ms}$ [46], which compares favorably with faststart response latencies of many fishes [47].

Response to 'Inside' Stimulation. Stimuli applied to the subumbrella may result in excitation of one or more of the motor giant axons. There are no mechanoreceptive sensory cells associated with these axons, but they lie very close to the surface and they and/or the lateral neurons coupled to them are probably stimulated by direct contact, as might occur when foreign bodies are sucked into the subumbrellar cavity. Stimulation of a motor giant anywhere along its length can evoke a sodium spike that propagates to all the other motor giants, evoking synchronized escape swimming. The pathway around the margin in this case is not the ring giant but a system of rootlet interneurons that run in the inner nerve ring (fig. 1B). Each motor giant is electrically coupled to rootlet interneurons that run out laterally on either side within the inner nerve ring, where they mingle in a zone of overlap with rootlet interneurons 'belonging' to the neighboring motor giants. Transmission between rootlet interneurons is chemical [7] and results in generation of action potentials that propagate to the next motor giant, and so on around the ring. Rootlet interneuron input can be recorded in motor giants close to the junctional region as attenuated action potentials (fig. 5E) - attenuated after passage through the gap junctions that occur here [48]. Though purely electrical in origin, these attenuated spikes function like the fast-rising, chemical EPSPs produced by ring giant input, generating sodium spikes [17] and they bear a striking (if superficial) resemblance to the chemical EPSPs in waveform.

Conduction along the rootlet interneuron chain occurs at $0.5 \mathrm{~m} \cdot \mathrm{s}^{-1}$, more slowly than along the ring giant, so response latency in this form of the escape response is probably longer than with outside stimulation, although this has not been measured.

As shown in the circuit diagram there are two-way excitatory interactions between the pacemaker and rootlet interneuron systems. Pacemaker impulses generate slow EPSPs in the rootlet interneurons but spikes in the rootlets generate spikes in the pacemaker neurons on a one-for-one basis. Thus, when the rootlet interneuron pathway is excited during escape swimming, the pacemaker system is also excited. The pacemaker neurons may fire repetitively if stimulated close to the time when they would normally generate a spontaneous burst. This explains why escape swims, whether due to outside or to inside stimulation, are sometimes followed by bursts of slow swimming. 


\section{Ionic Basis of $\mathrm{Na}^{+}$and $\mathrm{Ca}^{2+}$ Spikes in the Motor Giants}

The 'slow' EPSPs recorded from motor giants that represent pacemaker input depolarize the axon from -70 to $-51 \mathrm{mV}$, the threshold for initiation of calcium spikes. This corresponds to the voltage at which calcium current starts to flow in voltage clamp experiments [49] and in axon membrane patches [26]. In contrast, the 'fast' EPSPs seen during escape responses depolarize the axon to $-32 \mathrm{mV}$, corresponding to the voltage at which inward sodium current starts to flow [26]. As noted earlier, the peak of the calcium spike lies below the threshold for sodium spikes, so calcium spikes do not set off sodium spikes. All evidence to date from drug experiments and electrophysiology point to T-type $\mathrm{Ca}^{2+}$ channels as the portals for calcium influx in calcium spike electrogenesis. Another type of $\mathrm{Ca}^{2+}$ channel may play a role at neuromuscular synapses.

Repolarization involves a family of A-type potassium channels, of which three categories have been distinguished $[49,50]$. They have similar conductances, suggesting that they evolved by gene duplication, but they differ in their voltage dependencies and inactivation kinetics, and are accordingly referred to as 'fast', 'slow' and 'intermediate'. Rapid activation of the fast $\mathrm{K}^{+}$channels evidently serves to cut short the inward $\mathrm{Ca}^{2+}$ current near the peak of the calcium spike preventing the latter from reaching the threshold for sodium spikes. The same channels, together with the more slowly activating species, contribute to the repolarization of the sodium spike.

\section{Coordinated Tentacle Contractions Accompanying Swimming}

Typical specimens of Aglantha have 60-80 tentacles arranged around the margin. When the animal is fishing for food it stops swimming and sinks with the tentacles extended on all sides. Movement relative to the water mass is assisted by beating of the powerful cilia arranged in rows on either side of the tentacles. The cilia are borne on epithelial cells equipped with basal muscle processes that form part of the general, longitudinal muscle layer, and when these muscles contract, the cilia simultaneously undergo arrest [51]. Tentacles can respond to local stimuli by flexing independently, but during swimming they all contract. Aglantha differs markedly from other hydromedusae in the way these contractions are coordinated. Most medusae have a single, marginal conduction system that extends into the tentacles and is dedicated to coordina- tion of the tentacles. Its electrical correlates, originally termed 'marginal pulses' [52], were later described under several other names [2]. In Polyorchis it is termed the ' $\mathrm{B}$ ' system [53-55]. Nothing comparable to this system exists in Aglantha. Further, the tentacle contractions seen during escape behaviour differ markedly from those seen during slow swimming and are mediated by different neural pathways. Finally, Aglantha differs from all other known hydromedusae in having striated muscles in the tentacles [16]. These probably evolved in response to a need for rapid contractility during escape behavior, but they are responsible for the graded contractions seen at other times, being the only muscle fibers present.

The coordinated tentacle contractions observed during swimming are probably significant as a way of reducing drag and making locomotion more efficient, but the tentacles have an 'autotomy joint' at their bases and readily detach when tugged sharply [43], so the contractions that occur during swimming, particularly during escape swimming, may serve a secondary role in reducing the risk of 'accidental' autotomy.

The tentacles have two physiologically distinct conduction systems. Small potentials are associated with slow conduction at $<0.2 \mathrm{~m} \cdot \mathrm{s}^{-1}$ in a network of smaller neurites and mediate the slow contractions of graded amplitude seen in non-escape contexts. Larger events are conducted at $<0.9 \mathrm{~m} \cdot \mathrm{s}^{-1}$ in the tentacle giant axon and trigger rapid, all-or-none 'twitch' responses. The two systems are here termed the slowly-conducting tentacle system and the tentacle giant system, respectively $[57,58]$. We will now consider how these systems are brought into play during the two sorts of swimming.

Tentacle Contractions Accompanying Slow Swimming

The impulses generated by the pacemaker neurons during slow swimming trigger events not only in the motor giants but also in interneurons of the relay system (fig. $3 \mathrm{~A} 2, \mathrm{~A} 3$ ) that runs in parallel with it and this will, in the simplest scenario, be followed by excitation of the slow tentacle system resulting in orally-directed tentacle flexions. The amplitude of the tentacular response increases with each swim in a series of slow swims, eventually resulting in all the tentacles being tightly curled in close to the margin. This appears to be the basic role for the relay system - to bring about tentacle contractions during slow swimming.

Surprisingly, twitch contractions of the tentacles are sometimes seen during slow swimming, along with the graded, or tonic, sort. These are identical to the synchronized contractions seen during escape swimming and like 
them are conducted round the margin by impulses in the ring giant axon and down the tentacles in the tentacle giant system. It appears that the hard and fast distinction between escape and non-escape circuitry breaks down in this case as we normally associate ring giant activation exclusively with escape responses. The mechanism is described below.

\section{Tentacle Contractions Accompanying Escape}

Swimming following Outside Stimulation

As already noted, tactile and vibrational stimuli applied to the tentacles or margin lead to excitation of the ring giant axon. Events conducted around the margin by this unit automatically excite the tentacle giant system in all the tentacles, resulting in a powerful, unified, twitch response that slightly precedes the onset of swimming.

\section{Tentacle Contractions Accompanying Escape}

\section{Swimming following Inside Stimulation}

We have already seen that impulses generated in the rootlet interneuron system during escape swimming trigger activity in the pacemaker system, which may respond repetitively, producing a series of slow swims following the escape swim. This is not the end of the story, as impulses in the pacemaker system are always followed one-for-one, after a short delay, by impulses in the relay system (fig. 3A2, A3). Intracellular recordings show that the ring giant receives input in the form of EPSPs from both these sources and also from a third source, the carrier system which fires following the relay system, again after a short delay (fig. 3C1, C2). The EPSPs from these three sources appear sequentially in the ring giant, and the depolarizations sum, sometimes to spike threshold at about $-46 \mathrm{mV}$. A cascade of summing inputs from three sources, firing in sequence, is evidently necessary for spike production in the ring giant, no doubt because of the axon's large size and high membrane capacitance $[7,5,58]$.

We do not understand why the ring giant sometimes spikes and sometimes fails to spike in these circumstances, but whether it does so or not determines whether the resulting tentacle response will be of the fast-twitch or slow-graded sort. If the ring giant spikes, the tentacles will show the concerted twitch response. If it does not, and if the pacemaker system continues to fire repetitively, the tentacles will still show graded slow contractions owing to the direct activation of the slow tentacle system by the relay system. Sometimes the response seen appears inappropriate to the behavior. While a twitch contraction of the tentacles during slow swimming would be harmless, a single, slow contraction during escape swimming would seem virtually useless as it would do little to reduce tentacular drag. It might however reduce the risk of autotomy as the muscles in the autotomy zone would have developed some tonus.

Of the interneurons involved in communication with the ring giant, the carrier system has proved hardest to characterize. It can conduct slowly on its own but conducts rapidly at the same velocity as the ring giant when the latter conducts impulses. When firing in synchrony with the ring giant, its electrical correlates tend to be submerged in those of the latter so it is indistinguishable in extracellular recordings, or forms a minor part of a combined carrier/ring giant event (e.g. fig. 3C1). EPSPs representing carrier input are seen in intracellular recordings and are diminished by treatment with divalent cations, indicating chemical transmission. The system gets its name from the fact that it can 'carry' impulses around regions where the ring giant has been damaged. The impulses reappear in the ring giant on the other side. It seems to provide an input link between the ring giant and other systems, as in the cascade referred to above, and on the output side by transmitting excitation from the ring giant to the motor giants during escape swimming after outside stimulation, where the latency seems to call for a disynaptic connection. The carrier system also probably provides an input-output link between the ring giant and the tentacle giant system.

\section{Piggyback Interactions}

Piggybacking is a process seen in several hydrozoans where events propagated in one conduction system travel at an accelerated rate when a second, faster system running in parallel with it, is also excited. As in the children's game, one system rides 'piggyback' on the back of the other. The process was first noted in the stem of a siphonophore where the endoderm was found to be an excitable epithelium that conducted slowly on its own at $0.3 \mathrm{~m} \cdot \mathrm{s}^{-1}$. When giant neurons running in the ectoderm were simultaneously excited, propagating at velocities up to $3.0 \mathrm{~m} \cdot \mathrm{s}^{-1}$, conduction in the endoderm was accelerated to almost the same value. The ectoderm and endoderm were found to be connected by transmesogloeal bridges, with gap junctions between the epithelial cells of the two layers. The explanation advanced to explain piggybacking in this case was that events conducted in the giant axons depolarized the ectodermal myoepithelium through conventional synapses and that the depolarizations spread through gap junctions to the endoderm, assisting the forward spread of action currents, and hence increasing the speed of impulse propagation in the latter [59]. 
In jellyfish nerve rings, we have a similar situation with several conduction systems running in parallel. It has long been recognized that the individual axons lack glial sheaths $[1,60]$, although groups of them may be loosely bundled within epithelial processes. In Aglantha, piggyback interactions have been observed between several systems, as shown in figure 2 by squiggly-shafted arrows (an iconographic reference to a pig's tail). To take one example, the relay system conducting on its own never showed a conduction velocity exceeding $0.1 \mathrm{~m} \cdot \mathrm{s}^{-1}$, but when the pacemaker system was simultaneously active, relay velocities increased to $0.24 \mathrm{~m} \cdot \mathrm{s}^{-1}$, and when both the pacemaker and ring giant systems were active, relay velocity increased to $0.41 \mathrm{~m} \cdot \mathrm{s}^{-1}$ [57]. Likewise, the carrier system conducting on its own showed a conduction velocity of $<0.5 \mathrm{~m} \cdot \mathrm{s}^{-1}$ in a preparation where it conducted at $<2.0 \mathrm{~m} \cdot \mathrm{s}^{-1}$ in the piggyback mode, carried on the back of the ring giant [58].

The mechanisms for piggybacking in Aglantha are unclear, but observations on the effects of various drugs [57] suggest that it not always mediated either by gap junctions or by chemical synapses but may involve some sort of external 'field effect' [61, 62]. While such interactions between functionally distinct neuronal subsets might be explained away as an insulation defect related to the lack of proper glial sheaths, it appears that at least in some cases the process has been put to good use. Piggybacking may be important in the case of ring giant activation in escape behavior set off by inside stimulation where the ring giant requires sequential input from the pacemaker, relay and carrier systems within a restricted time frame in order to reach spike threshold. Piggybacking may help maintain these inputs in an optimal time relationship.

\section{Pathways Mediating Feeding Behavior}

When fishing for food, Aglantha typically sinks inverted with outstretched tentacles. Prey contacting a tentacle are captured by discharge of nematocysts and held to the tentacle by the discharged thread. The tentacle then bends toward the margin ('oral tentacle flexion'). On reaching the margin, the food is held there until transferred to the mouth, which lies at the tip of the muscular, prehensile manubrium (fig. 1A). The manubrium bends across toward the point where the food is located (the 'pointing' response described in other medusae [35, 63], while the oral lips expand ('lip flaring') and apply themselves to the prey. The prey is then engulfed and digested.
Animals which were swimming at the start of feeding stop doing so while food is being transferred to the manubrium and engulfed ('swimming inhibition'). The action systems involved in these four steps [39] will now be considered.

Oral Tentacle Flexions. These movements are of the slow type, mediated by the slow tentacle system described above. The flexions affect only those tentacles directly stimulated, others remaining extended. Neurosensory cells bearing short sensory processes occur in the slow tentacle net and probably trigger the flexions.

Pointing. Bundles of small axons run radially from the margin to the manubrium where they selectively innervate muscle bands located in the walls of the manubrium. There are eight such pathways, each with its 'own' muscle band. These pathways in Aglantha have been termed the flexion system (F, in fig. 2), because they mediate unilateral manubrial flexions in the pointing response. The flexion system originates at least in part from sensory cells (fig. 4A, E), referred to as type 2 sensory cells $[38,41]$ or $F$ cells [here and 39,44], which are located at the margin. Sensory neurons in the tentacles form a separate nerve plexus there (TF in fig. 2) that appears to be part of the same system. Though originating from sensory cells, flexion axons function as a motor pathway in exciting the pointing muscles. The radial flexion tracts are seen as bundles of small axons in TEM sections (fig. 4D). They and the flexion cells show FMRFamide-like immunoreactivity, another reason for the $\mathrm{F}$ designation. They are interconnected at the margin by axons running circularly in the nerve rings. Impulses through-conduct via these circular connections to all eight tracts, but the most strongly excited manubrial muscles are those closest to the site of the stimulus, and thus pointing in that direction results.

The presence of FMRFamide-like immunoreactivity in the flexion system neurons, as detected by fluorescent and immunogold labelling [38, 64], suggests that peptidergic transmission occurs at the neuromuscular junctions involved in pointing. The peptide in question has not been sequenced, but RF- and related short-chain peptides are widely distributed through the Cnidaria and have frequently been implicated as neurotransmitters or neuromodulators [65].

Lip Flaring. At the same time as the manubrium points to a site of prey capture, its lips flare wide open, preparatory to attaching to the prey. Lip flaring is a symmetrical response involving the ectodermal longitudinal muscles on all sides of the manubium. The response is mediated not by nerves but by the epithelium forming the walls of the endodermal radial canals, termed the $\mathrm{E}_{\mathrm{n}}$ pathway (fig. 2). It is not known how impulses cross between the 
endoderm and the ectoderm, but epithelial bridges cross the intervening mesogloeal layer, and nerves run in both layers of the manubrium. Conduction occurs circularly both at the margin (in the ring canal) and in the manubrium itself so endodermal epithelial impulses initiated at any point spread throughout the entire system. The system conducts centripetally in response to food at the margin, but later during feeding it conducts centrifugally as bursts of endodermal epithelial impulses are generated locally in the manubrium during ingestion. The lip flarings seen at this stage help spread the lips around the food. These bursts are probably generated by neuronal pacemakers even though they then propagate in an epithelium. Two-way neuro-epithelial interactions are known for a number of other animals [32].

Swimming Inhibition. In attempts to maintain captive Aglantha by feeding them with brine shrimp larvae it was noticed that animals which were swimming stopped while ingesting food. Experiments later showed that swimming could be arrested by artificially stimulating the endodermal epithelial conduction system (fig. 3E). The duration of inhibition depends on the number and frequency of endodermal epithelial impulses arriving at the margin, and some degree of inhibition persists even after swimming has been resumed. As noted, endodermal epithelial impulses can propagate in either direction along the radial canals and are generated in bursts during ingestion. While it is not clear precisely how the impulses inhibit the swim pacemakers, it is known that there are trans-mesogloeal processes connecting the endo- and ectoderm at the margin in the vicinity of the nerve rings, and that some groups of nerves in the nerve rings are enveloped by processes of epithelial cells. Neither gap junctions nor synapse-like structures have been seen where the epithelial cells contact the nerves however.

We have seen earlier that epithelial impulses generated in the exumbrellar ectoderm inhibit swimming in Aglantha [36] and that intracellular recordings from the pacemaker neurons in Polyorchis showed hyperpolarizations during swimming inhibition [23]. It seems likely that whatever mechanism mediates the inhibition in these cases also mediates it in the case of swimming inhibition during feeding. However, endodermal epithelial impulses propagated in the canals during feeding do not spread across to the ectoderm at the margin or travel up the exumbrella, nor vice versa, so the two epithelial pathways are shown separately in figure 2 .

\section{Conclusions}

\section{Evolution of Escape Circuitry}

Many of the features peculiar to Aglantha can be seen as adaptations to life in the competitive mid-water environment. Observations from a manned submersible in the waters around Vancouver Island leave a vivid impression of the dense populations of euphausiids, copepods and other crustaceans living at the very same depths where Aglantha are most concentrated [10]. Aglantha's acute vibrational sensitivity and unique escape behaviour may well have evolved as an adaptation to life in heavily populated mid-water zones, where they would help reduce the risk of damaging contact with their numerous, spiny crustacean cohabitants. Indeed, we have observed escape responses occurring in the natural habitat following chance contact with crustaceans [author, unpubl.]. On the other hand, Aglantha lacks ocelli, shows no 'shadow response' and lacks visual neural circuitry of the sort described for Polyorchis [55, 66-68], a species that lives much closer to the surface.

Aglantha has evolved a special set of components enabling it to swim and to contract its tentacles in two fundamentally different ways (escape and non-escape) and this has required wholesale modification of the basic systems which we assume were inherited from the common ancestor. Of the interneuron systems described here, the pacemaker system can be seen as a basic medusan component inherited more or less intact, but all the other neural sub-systems are unique to Aglantha, or have been modified to the extent that their origins can no longer be recognized. Even the pacemaker system has undergone drastic modification of its input-output relationships. Its primary output is no longer to the swim muscles (which have lost the ability for myoid conduction) but rather to neural components in the slow swimming motor pathway. At the same time it is postsynaptic to the rootlet interneurons, and so is excited during escape swimming as well as during slow swimming. In its turn, it provides input to the relay system, causing it to spike, and to the carrier/ring giant system, causing EPSPs which may sum with those due to relay input in bringing the ring giant to spike threshold.

The relay system can be seen as a key component required for activation of the slow tentacle system and thus for bringing about graded tentacle contractions during slow swimming, but it has the additional property of exciting the carrier/ring giant system. If the latter responds by spiking, the tentacle giant system will be activated, resulting in twitch contractions of the tentacles. We

\footnotetext{
$\overline{16} \quad$ Neurosignals 2004;13:5-19
} 
see the carrier system as an adjunct to the ring giant mediating the latter's interactions with other systems, and with no known counterpart in other medusae.

Turning to the tentacles, the tentacle giant system has no counterpart in other medusae but presumably evolved, along with the striated muscles, to provide for short-latency, twitch contractions during escape behaviour. The slow tentacle system may represent a relic of the system that provides for coordinated tentacle contractions in other medusae [references in 2], but if so it has lost those portions running in the outer nerve ring that elsewhere interconnect the tentacles and is reduced to the status of a local action system.

The ring, motor and tentacle giant axons are all unique to Aglantha. The ring giant is highly peculiar in being a torus, the interior occupied by a fluid-filled vacuole [16]. The possibility has been suggested that it evolved from an excitable epithelium rather than from nerves [69], but this is quite uncertain. The tentacle giants also have a large central vacuole running their entire length [51]. The motor giants are unique in their ability to conduct two sorts of action potential, the only nerves known to be capable of this feat.

Despite their enigmatic origins and unusual, specialized features, these axons endow Aglantha with a startle response that bears comparison with Mauthner-mediated C-start responses of fishes. In one respect, however, unless perhaps our findings made under lab conditions are not truly representative of normal behaviour, the control of tentacle contractions during swimming seems less than $100 \%$ efficient. While the concerted twitch responses seen with outside stimulation of escape swimming are predictable and efficiently serve the purpose of reducing drag prior to the initiation of the violent swimming contraction, similar contractions are sometimes seen during slow swimming when one would simply expect slow, graded contractions. Further, in the case of inside stimulation leading to escape swimming, the tentacle contractions may be of the inappropriate, slow sort rather than fast, concerted twitches. Even where the twitch response is seen, it ensues after the initiation of the swim rather than before it owing to the cumulative delays involved in serial activation of the pacemaker, relay and carrier/ring giant systems. Its effectiveness in reducing drag must therefore be much reduced. One can only conclude that natural selection has not yet completed the task of sorting out all the problems raised by the introduction of special escape circuitry and the need to integrate these components with the existing slow circuitry.

Jellyfish Neural Circuitry
No such problem applies to the activation of the swim muscles during the two sorts of swimming - the distinction is always a clear-cut one. The fast response depends on sodium spikes in the motor giants and the slow one on calcium spikes and the two do not overlap. The tentacle responses in contrast rely on interactions between several different conduction systems which, by nature, involves a more 'noisy' type of decision-making process.

\section{Aglantha's Interesting Use of Excitable Epithelia}

The loss of protective, 'crumpling' behavior of the sort seen in other hydromedusae is probably related to Aglantha's development of a rapid, escape swimming response. It no longer needs both means of protecting itself. At the same time, it has retained epithelial excitability in the exumbrella and uses this pathway to inhibit swimming in the event of collision with foreign objects. Finally, it has retained excitability in the endodermal radial canals (originally involved in crumpling) and uses these pathways to bring about lip flaring during feeding, and to inhibit swimming while the manubrium is ingesting food. It would seem that Aglantha has effectively commandeered components left over from an action system it no longer needs and redeployed them for use in a very different context.

\section{Aglantha as a 'Model'}

Choice of animals for neurophysiological work (e.g. Sarsia, Stomotoca, Aequorea, Polyorchis) has been influenced more by factors of convenience, such as their predictable appearance at certain sites and seasons, than by how 'typical' they are, and Aglantha is no exception. It is one of the few holoplanktonic species that can be counted on to appear every year close to a major marine station. Its special neural and muscular adaptations as described in this review are probably also present in other rhopalonematid medusae but not so far as we know in members of other Families [70]. This may limit Aglantha's usefulness as a model, but members of all medusan families have their own peculiarites and not enough species have been examined in sufficient depth for it to be easy to pick any one species as the best model for the group as a whole.

This being said, it must be admitted that Aglantha is quite unlike the species named above and is indeed something of 'a special case' [6]. The presence of giant axons and the substitution of neural for myoid conduction in the swim muscles set it apart. The dual innervation of both the tentacular and swim muscles and the way in which the tentacles are coordinated are also unique features. It is not 
even clear that Aglantha conforms to the well-known paradigm established for other hydromedusae (fig. 7 in ref. [22]) in which the various neural subsets are composed of electrically coupled units, with chemical synapses restricted to interfaces between subsets. It is customary to think of the pathways in medusan nerve rings and elsewhere as 'compressed nerve nets' [2], but if the compact bundles of axons comprising the flexion system are anything to go by, this may not apply in the case of Aglantha. These axons innervate the pointing muscles, traveling from the margin to the manubrium. They do not appear to synapse or make gap junctions with one other, and can be regarded as 'a nerve' in the same way that we speak of the vagus or sciatic nerve [39].

It is not just Aglantha's neuromuscular organization that sets it apart, but its whole biology. All the 'conven- tional' species named above live in relatively shallow coastal waters, being tied to sessile hydroid stages. Aglantha has no hydroid stage and is often found thousands of miles from the nearest land. It has evolved for a very different sort of life. It has been extremely instructive to work on, not because it typifies hydromedusae as such, but because it shows what the cnidarian body plan is capable in terms of nervous organization. For a diploblastic, acephalic animal it has an astonishingly sophisticated nervous system. One must concur with Satterlie [6] that 'any reticence in acknowledging the complexity of the central nervous system of these animals, and of their integrative abilities, should be abandoned'. Much still remains to be explored and future workers will find the task a rewarding one.

\section{References}

1 Horridge GA, Chapman DM, Mackay B: Naked axons and symmetrical synapses in an elementary nervous system. Nature 1962;193: 899-900.

2 Spencer AN, Schwab WE: Hydrozoa; in Shelton GAB (ed): Electrical Conduction and Behaviour in 'Simple' Invertebrates. Oxford, Clarendon Press, 1982, pp 73-148.

3 Mackie GO: The elementary nervous system revisited. Am Zool 1990;30:907-920.

4 Romanes GJ: Preliminary observations on the locomotor system of medusae. Phil Trans Roy Soc Lond [B] 1876;166:269-313.

5 Romanes GJ: Further observations on the locomotor system of medusae. Phil Trans Roy Soc Lond [B] 1877;167:659-752.

6 Satterlie RA: Neuronal control of swimming in jellyfish: A comparative story. Canad J Zool 2002;80:1654-1669.

7 Mackie GO, Meech RW: Central circuitry in the jellyfish Aglantha digitale. III. The rootlet and pacemaker systems. J Exp Biol 2000;203: 1797-1807.

8 Anderson PAV, Schwab WE: Recent advances and model systems in coelenterate neurobiology. Progr Neurobiol 1982;19:213-236.

9 Satterlie RA, Spencer AN: Organization of conducting systems in 'simple' invertebrates: Porifera, Cnidaria and Ctenophora; in Ali MA (ed): Nervous Systems in Invertebrates. New York, Plenum, 1987, pp 213-264.

10 Mackie GO, Mills, CE: Use of Pisces IV submersible for zooplankton studies in coastal waters of British Columbia. Can J Fish Aquat Sci 1983;40:763-776

11 Mackie GO: Midwater macroplankton of British Columbia studied by submersible Pisces $I V$. J Plank Res 1985;7:753-777.
12 Hertwig O, Hertwig R: Das Nervensystem und die Sinnesorgane der Medusen. Leipzig, Vogel, 1878.

13 Gladfelter WB: A comparative analysis of the locomotory systems of medusoid Cnidaria. Helgoländ Wiss Meeresunters 1973;25:228272.

14 Singla CL: Locomotion and neuromuscular system of Aglantha digitale. Cell Tissue Res 1978;188:317-327.

15 Donaldson S, Mackie GO, Roberts A: Preliminary observations on escape swimming and giant neurons in Aglantha digitale (Hydromedusae: Trachylina). Can J Zool 1980;58:549_ 552.

16 Roberts A, Mackie GO: The giant axon escape system of a hydrozoan medusa, Aglantha digitale. J Exp Biol 1980;894:303-318.

17 Meech RW, Mackie GO: Two escape swim inputs in the jellyfish Aglantha digitale. J Physiol 2001;536P

18 Kerfoot PAH, Mackie GO, Meech RW, Roberts A, Singla CL: Neuromuscular transmission in the jellyfish Aglantha digitale. J Exp Biol 1985;116:1-25.

19 Satterlie RA, Spencer AN: Neuronal control of locomotion in hydrozoan medusae. J Comp Physiol 1983;150:195-206.

20 Lin Y-CJ, Gallin WJ, Spencer AN: The anatomy of the nervous system of the hydrozoan jellyfish, Polyorchis penicillatus, as revealed by a monoclonal antibody. Invert Neurosci 2001;4: 65-75.

21 Mackie GO: Slow swimming and cyclical 'fishing' behavior in Aglantha digitale (Hydromedusae: Trachylina). Can J Fish Aquat Sci 1980; 37:1550-1556

22 Spencer AN, Satterlie, RA: Electrical and dyecoupling in an identified group of neurons in a coelenterate. J Neurobiol 1980;11:13-19.
23 Spencer AN: The parameters and properties of a group of electrically coupled neurones in the central nervous system of a hydrozoan jellyfish. J Exp Biol 1981;93:33-50.

24 Anderson PAV, Mackie GO: Electrically coupled, photosensitive neurons control swimming in a jellyfish. Science 1977;197:186-188.

25 Mackie GO, Meech RW: Separate sodium and calcium spikes in the same axon. Nature 1985; 313:791-793

26 Meech RW, Mackie GO: Synaptic potentials underlying spike production in motor giant axons of Aglantha digitale. J Neurophysiol 1995; 74:1662-1670.

27 Arkett SA: Hydromedusan photophysiology: An evolutionary perspective; in Anderson PAV (ed): Evolution of the First Nervous Systems. New York, Plenum, 1989, pp 373-388.

28 Martin VJ: Photoreceptors in cnidarians. Can J Zool 2002;80:1703-1722.

29 Moroz LL, Mackie GO, Meech RW: The distrribution and action of nitric oxide in the jellyfish Aglantha digitale (Hydromedusae: Trachylina). J Physiol 1997;504P.

30 Mackie GO: Neuroid conduction and the evolution of conducting tissues. Q Rev Biol 1970; 45:319-332.

31 Spencer AN: Non-nervous conduction in invertebrates and embryos. Am Zool 1974;14: 917-929.

32 Anderson PAV: Epithelial conduction: Its properties and functions. Progr Neurobiol 1980;15:161-203.

33 Josephson RK Communication by conducting epithelia; in Cohen MJ, Strumwasser F (eds): Comparative Neurobiology: Modes of Communication in the Nervous System. New York, Wiley-Interscience, 1985, pp 133-148. 
34 Mackie GO: Neurobiology of Stomotoca. II. Pacemakers and conduction pathways. J Neurobiol 1975;6:357-378.

35 Mackie GO, Singla CL: Neurobiology of Stomotoca. I. Action systems. J Neurobiol 1975;6: 339-356.

36 Mackie GO, Singla CL: The role of epithelial conduction in the behaviour of Aglantha digitale (O.F. Müller, 1776) (Hydromedusae: Rhopalonematidae). Proc 6th Int Conf Coelenterate Biology. Leiden, Nat Natuurhist Museum, 1997, pp 307-313.

37 Satterlie RA: Central generation of swimming activity in the hydrozoan jellyfish Aequorea Aequorea. J Neurobiol 1985;16:41-55.

38 Mackie GO, Singla CL, Stell WK: Distribution of nerve elements showing FMRFamide-like immunoreactivity in hydromedusae. Acta Zool (Stockh) 1985;66:199-210.

39 Mackie GO, Marx RM, Meech RW: Central circuitry in the jellyfish Aglantha digitale. IV. Pathways coordinating feeding behaviour. J Exp Biol 2003;in press.

40 Arkett SA: Diel vertical migration and feeding behavior of a demersal hydromedusan (Polyorchis penicillatus). Can J Fish Aquat Sci 1984; 41:1837-1843.

41 Singla CL: Fine structure of the sensory receptors of Aglantha digitale (Hydromedusae: Trachylina). Cell Tiss Res 1983;231:415-425.

42 Gladfelter WB: Structure and function of the locomotory system of Polyorchis montereyensis (Cnidaria, Hydrozoa). Helgoländ Wiss Meeresunters 1972;23:38-79.

43 Bickell-Page LR, Mackie GO: Tentacle autotomy in the hydromedusa Aglantha digitale (Cnidaria): An ultrastructural and neurophysiological analysis. Phil Trans Roy Soc Lond [B] 1991; 331:155-170.

44 Arkett SA, Mackie GO, Meech RW: Hair cel mechanoreception in the jellyfish Aglantha digitale. J Exp Biol 1988;135:329-342.

45 Spencer AN, Przysiezniak J, Acosta-Urquidi J Basarsky TA: Presynaptic spike broadening reduces junctional potential amplitude. Nature 1989;340:636-638.
46 Mackie GO: Fast pathways and escape behavior in Cnidaria; in Eaton RC (ed): Neural Mechanisms of Startle Behavior. New York, Plenum 1984, pp 15-43.

47 Eaton RC, Hackett JT: The role of the Mauthner cell in fast-starts involving escape in teleost fishes; in Eaton RC (ed): Neural Mechanisms of Startle Behavior. New York, Plenum, 1984, pp 213-266.

48 Weber C, Singla CL, Kerfoot PAH: Microanatomy of the subumbrellar motor innervation in Aglantha digitale (Hydromedusae: Trachylina). Cell Tissue Res 1982;223:305-312.

49 Meech RW, Mackie GO: Ionic currents in giant motor axons of the jellyfish, Aglantha digitale. J Neurophysiol 1993;69:884-893.

50 Meech RW, Mackie GO: Potassium channel family in giant motor axons of Aglantha digitale. J Neurophysiol 1993;69:894-901.

51 Mackie GO, Nielsen C, Singla CL: The tentacle cilia of Aglantha digitale (Hydrozoa: Trachylina) and their control. Acta Zool (Stockh) 1989; 70:133-141

52 Passano LM: Pacemakers and activity patterns in medusae. Am Zool 1965;5:465-481.

53 Spencer AN: Neurobiology of Polyorchis. I. Function of effector systems. J Neurobiol 1978; 9:143-157.

54 Spencer AN: Neurobiology of Polyorchis. II. Structure of effector systems. J Neurobiol 1979;10:95-117.

55 Spencer AN, Arkett SA: Radial symmetry and the organization of central neurones in a hydrozoan jellyfish. J Exp Biol 1984;110:69-90.

56 Mackie GO, Meech RW: Central circuitry in the jellyfish Aglantha digitale. I. The relay system. J Exp Biol 1995; 198:2261-2270.

57 Mackie GO, Meech, RW: Central circuitry in the jellyfish Aglantha digitale. II. The ring giant axon and carrier systems. J Exp Biol 1995;198: 2271-2278.

58 Mackie GO: The control of fast and slow muscle contractions in the siphonophore stem; in Mackie GO (ed): Coelenterate Ecology and Behavior. New York, Plenum, 1976, pp 647659.
59 Jha RK, Mackie GO: The recognition, distribution and ultrastructure of hydrozoan nerve elements. J Morph 1967;123:43-61.

60 Bullock TH: Facilitation of conduction rate in single nerve fibres. J Physiol (Lond) 1951;114: 89-97

61 Bullock TH: Comparative neuroethology of startle, rapid escape and giant fiber-mediated responses; in Eaton RC (ed): Neural Mechanisms of Startle Behavior. New York, Plenum, 1984, pp 1-13.

62 Horridge GA: The nerves and muscles of medusae. II. Geryonia proboscidalis Eschscholtz. J Exp Biol 1955;32:555-568.

63 Singla CL, Mackie GO: Immunogold labelling of FMRFamide-like neuropeptide in neurons of Aglantha digitale (Hydromedusae: Trachylina). Can J Zool 1991;69:800-802

64 Grimmelikhuijzen CJP, Williamson M, Hansen GN: Neuropeptides in cnidarians. Can J Zool 2002;80:1690-1702

65 Arkett SA: The shadow response of a hydromedusan (Polyorchis penicillatus): Behavioral mechanisms controlling diel and ontogenenic vertical migration. Biol Bull 1985;169:297312.

66 Arkett SA, Spencer AN: Neuronal mechanisms of a hydromedusan shadow reflex. I. Identified reflex components and sequence of events. J Comp Physiol 1986;159:201-213.

67 Spencer AN: Neuronal mechanisms of a hydromedusan shadow reflex. II. Graded response of reflex components, possible mechanisms of photic integration and functional significance. J Comp Physiol 1986;159:215-225.

68 Mackie GO: Evolution of cnidarian giant axons; in Anderson PAV (ed): Evolution of the First Nervous Systems. New York, Plenum, 1989, pp 395-407.

69 Mills CE, Mackie GO, Singla CL: Giant nerve axons and escape swimming in Amphogona apicata with notes on other hydromedusae. Can J Zool 1985;63:2221-2224.

70 Moroz LL, Meech RW, Sweedler JV, Mackie GO: Nitric oxide regulates swimming in the jellyfish Aglantha digitale. J Comp Neurol, in press. 